Document downloaded from:

http://hdl.handle.net/10251/37296

This paper must be cited as:

Bonastre Cano, JA.; Molina Puerto, J.; Galván, J.C.; Cases, F. (2014). Charaterization of polypyrrole/phosphotungstate membranes by electrochemical impedance spectroscopy. Synthetic Metals. 187:37-45. doi:10.1016/j.synthmet.2013.10.020.

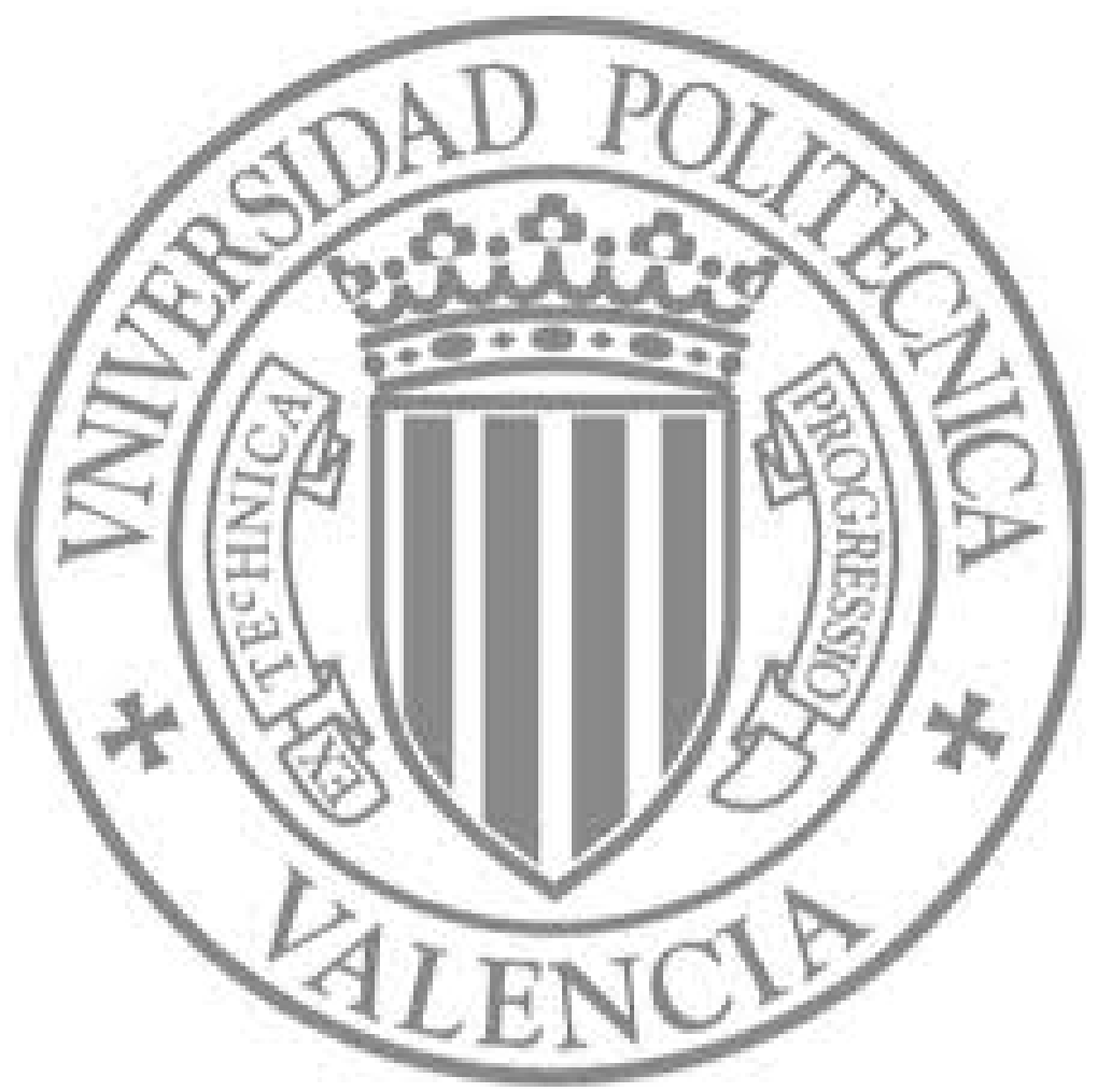

The final publication is available at

http://dx.doi.org/10.1016/j.synthmet.2013.10.020

Copyright Elsevier 


\title{
Characterization of polypyrrole/phosphotungstate membranes by electrochemical impedance spectroscopy
}

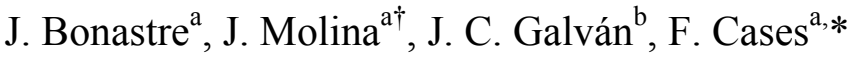 \\ ${ }^{a}$ Departamento de Ingeniería Textil y Papelera, EPS de Alcoy, Universitat Politècnica \\ de València, Plaza Ferrándiz y Carbonell s/n, 03801 Alcoy, Spain \\ ${ }^{b}$ Centro Nacional de Investigaciones Metalúrgicas, CSIC, Avda. Gregorio del Amo 8, \\ 28040 Madrid, Spain
}

\begin{abstract}
The aim of this study was to design and prepare multifunctional $\mathrm{PPy} / \mathrm{PW}_{12} \mathrm{O}_{40}{ }^{3-}$ membranes useful for the development of smart textile fabrics and wastewaters treatments based on the application of electrochemical techniques. These $\mathrm{PPy} / \mathrm{PW}_{12} \mathrm{O}_{40}{ }^{3-}$ membranes have been characterized by means of electrochemical impedance spectroscopy by using electrochemical cells with different configurations based on the use of two-, three-, or four-electrode experiments. The activation energy of the films in the temperature range $35-70^{\circ} \mathrm{C}$ was $170 \mathrm{meV}$. It has been demonstrated that after measuring the PPy films in different $\mathrm{NaCl}$ solutions, both the rate of ionic exchange and the diffusion processes through the membrane are faster for more concentrated solutions. Ionic exchange and diffusion were very prevented with a large cation as tetramethylammonium. The impedance spectra obtained with metal/polymer/electrolyte configuration show that the electrical conduction developed through coatings in strong acid solution is controlled by finite-length diffusion
\end{abstract}


processes with reflective boundary conditions. At $\mathrm{pH} 13$, the electrical response proceeds through the oxide layer ( $\mathrm{Fe}$ and $\mathrm{Cr}$ oxides) and the steel/electrolyte interface. In this case, the polymeric coating is very porous due to the counter-ion disintegration. The decomposition of the counter-ion was corroborated by means of energy dispersive X-ray and Fourier transform infrared spectroscopy.

Keywords: Polypyrrole; phosphotungstate; free-standing film; membrane; electrochemical impedance spectroscopy.

* Corresponding author. Fax.: +34966528438

E-mail address: fjcases@txp.upv.es (Prof. F. Cases)

$\dagger$ Present address: Energy Technological Institute, Applied Chemistry Department. Avda. Juan de la Cierva, 24. Parque Tecnológico de Valencia, 46980 Paterna, Spain.

\section{Introduction}

A great diversity of conducting polymers such as polyacetylene, poly(p-phenylene), poly(p-phenylenevinylene), polypyrrole, polyaniline, polythiophene or polyfurane, have been studied during the last three decades due to their promising properties as revolutionary materials [1]. The present study is focussed on polypyrrole because it can be electropolymerized as thick films and maintains good conductivity up to $\mathrm{pH} 10$ [2]. Polyoxometalates (POMs) can be possible candidates to be used as conter-ions in these polypyrrole polymerization processes. POMs are small oxide clusters whose size and 
solubility have caused them to be traditionally considered within the framework of molecular chemistry. They are indeed complex molecules with several metallic ions coordinated by shared oxide ions, forming a highly symmetrical metal oxide cluster [1]. POMs present the possibility to produce a hybrid material when combined with conducting polymers such as polypyrrole.. The phosphotungstic acid, $\mathrm{H}_{3} \mathrm{PW}_{12} \mathrm{O}_{40}$, has been the polyoxometalate chosen in this work as a counter-ion to be immobilized within the polymeric matrix in order to get compact and hard hybrid material. The molecular structure of phosphotungstic acid can be observed in the reference [3]. An idealized scheme of the structure of the molecular material formed between polypyrrole and phosphotungstate anion can be seen in $[4,5]$. The new material polypyrrole/ $\mathrm{PW}_{12} \mathrm{O}_{40}{ }^{3-}$ has higher density and conductivity than polypyrrole alone [6]. The presence of ionic active species immobilized in the polymeric matrix forces the cations instead of the anions present in the medium to diffuse through the polymer structure when an oxidation or a reduction reaction occurs. In addition, POMs are anions of high volume and charge, so their diffusion coefficient is low, and the exchange with anions present in the solution is negligible.

Electrochemical impedance spectroscopy (EIS) is a powerful technique that can provide information about charge transfer and ionic transfer processes within the film. A symmetrical configuration metal/polymer/metal can provide information about electronic transport. On the other hand the symmetrical configuration solution/polymer/solution provides information about the ionic transport. The asymmetrical configuration metal/polymer/solution provides information about both phenomena; electronic and ionic transport. 
The solution/polymer/solution configuration has been employed to study the electrochemical properties of $\mathrm{PPy} / \mathrm{PW}_{12} \mathrm{O}_{40}{ }^{3-}$ free-standing films in different solutions. Different studies have been published about this topic. Ehnrenbeck et al. [7] studied the ion conductivity and permselectivity of polypyrrole in dependence of the oxidation state. By oxidation or reduction of the polymer backbone, the membrane could be switched between anion or cation permselectivity. Ehnrenbeck et al. [8] also carried out EIS measurements of polypyrrole in $0.1 \mathrm{M} \mathrm{KCl}$ solution. The impedance of the membrane was measured as function of the film thickness and the redox potential. The data were analyzed with a theory of a macroscopically homogeneous porous membrane. J. Tietje-Girault et al. [9] obtained free-standing polypyrrole membranes from films on stainless steel. The membrane resistivity of the reduced films in $0.5 \mathrm{~mol} \mathrm{dm}{ }^{-3} \mathrm{KCl}(\mathrm{aq})$ at $295 \mathrm{~K}$ was $\sim 1 \cdot 10^{6} \Omega \mathrm{cm}$, while the resistivity of the oxidized membrane was $2700 \Omega$ cm. C. Deslouis et al. $[10,11]$ modeled the impedance response of free-standing membranes taking into account the effect of the diffusion coefficients, charge-transfer resistance, and double layer capacitance at the interfaces. It was thus shown how some ambiguities of the impedance to either the polymer/electrode or polymer/electrolyte interfaces may be eliminated by this comparison. They also studied the polypyrrole film behavior by ac impedance spectroscopy both in a free-standing membrane and in a modified electrode arrangement. The experimental results allowed to obtain both transport (diffusion coefficients, and ion concentration and electron-exchanging sites) and interfacial parameters (charge transfer resistances and double layer capacitances). C. Deslouis et al $[12,13]$ also prepared free-standing polypyrrole membranes to obtain experimental current-potential characteristics and impedance diagrams in the presence of electrolytes containing redox couples. They also studied the impedance of redox 
reactions. However polyoxometalates have not been employed as counter-ions in electrosynthesis processes of conductive polymers that to the best of our knowledge have not been reported before.

Two of the main purposes of our research group are (i) to design smart textile fabrics from porous materials, with conductive properties or working as electrical barriers depending of the $\mathrm{pH}$ of the media [14-25] and (ii) to develop new wastewaters treatments by electrochemical techniques [26-31]. Our research group has performed the synthesis of $\mathrm{PPy} / \mathrm{PW}_{12} \mathrm{O}_{40}{ }^{3-}$ organic-inorganic hybrid material on polyester yarns and subsequent weaving to obtain smart conductive fabrics. Smart textile fabrics with LED's mounted in different fabrics and circuits embroidered in leather have been obtained [32]. An important goal in these research fields is to know the behavior of membranes and electrocatalytic electrodes coated with thin films able to work in both strong acid and basic media. For this purpose, $\mathrm{PPy} / \mathrm{PW}_{12} \mathrm{O}_{40}{ }^{3-}$ free-standing membranes and $\mathrm{PPy} / \mathrm{PW}_{12} \mathrm{O}_{40}{ }^{3-}$ coated stainless steel samples were immersed in $\mathrm{pH} \sim 0$ and $\mathrm{pH} \sim 13$ solutions to evaluate their electrical response by EIS and to check their possible applicability in these fields.

\section{Material and methods}

\subsection{Reagents and materials}

Analytical grade pyrrole, acetonitrile, sulphuric acid, sodium sulphate and sodium hydroxide were purchased from Merck. Analytical grade phosphotungstic acid hydrate and sodium chloride were supplied by Fluka. Normapur acetone was from Prolabo. Tetramethylammonium chloride was purchased from Panreac. Ultrapure water was obtained from an Elix 3 Millipore-Milli-Q Advantage A10 system with a resistivity near 
to $18.2 \mathrm{M} \Omega \cdot \mathrm{cm}$. Where necessary, solutions were deoxygenated by bubbling nitrogen (N2 premier X50S).

2.2. Electrochemical synthesis of polypyrrole/ $/ \mathrm{PW}_{12} \mathrm{O}_{40}{ }^{3-}$ on stainless steel Electrosynthesis was performed using an Autolab PGSTAT302 potentiostat/galvanostat. All experiments were conducted at room temperature and in non-stirred solutions. Electropolymerization of pyrrole was performed on stainless steel electrodes (plates of 2 $\mathrm{cm} \times 3 \mathrm{~cm} \times 0.1 \mathrm{~cm})$; the chemical composition in weight (\%) was: $\mathrm{C} \leq 0.050$, Si 0.750 , $\mathrm{Mn} \leq 2.000, \mathrm{P} 0.040, \mathrm{~S} 0.015, \mathrm{Cr} 18-19, \mathrm{Cu} 8.5-9$. Before the electrosynthesis, stainless steel electrodes were degreased with acetone, mechanically polished to obtain a smooth surface and then, cleaned with ultrapure water in an ultrasonic bath. The counter electrodes were also made of stainless steel and the same pretreatment was applied to them. All potentials were referred to the $\mathrm{Ag} / \mathrm{AgCl}(3 \mathrm{M} \mathrm{KCl})$ reference electrode. Oxygen was removed from the synthesis solution by bubbling $\mathrm{N}_{2}$ gas and then a $\mathrm{N}_{2}$ atmosphere was maintained.

For the electropolymerization process, the pretreated electrode was immersed in a 0.01 $\mathrm{M} \mathrm{H}_{3} \mathrm{PW}_{12} \mathrm{O}_{40}+0.2 \mathrm{M}$ pyrrole solution (acetonitrile medium). A potentiostatic polarization was started between $-0.29 \mathrm{~V}$ and $+0.86 \mathrm{~V}$, staying the working electrode at $+0.86 \mathrm{~V}$ during the necessary time to achieve the desired electrical charge $\left(0.5 \mathrm{C} \mathrm{cm}^{-2}\right)$. In this way, stainless steel coated with polypyrrole was obtained. To obtain PPy freestanding films (membranes), the films were detached from the metallic substrate by using a sharp level. The estimated thickness of both films and membranes was approximately $3.8 \mu \mathrm{m}$ (see section 3.1 ). 


\subsection{Electrochemical impedance spectroscopy characterization}

Electrochemical impedance spectroscopy (EIS) measurements were performed in the $10^{4}$ to $10^{-2} \mathrm{~Hz}$ frequency range by using an Autolab PGSTAT302

potentiostat/galvanostat. The amplitude of the sinusoidal voltage was $\pm 10 \mathrm{mV}$. Each measurement was carried out at a constant imposed potential equal to the stabilized open circuit potential at the beginning of the experiment.

The electrical characterization of dry polymer pellets at variable temperature was carried out in the temperature range $35-70^{\circ} \mathrm{C}$ [18]. A furnace Carbolite CTF 12/65/550 was employed to control the temperature with the Settemp 3.0 software. A temperature cell GF-800 was employed to carry out EIS measurements based on the use of two electrode experiments, in which the pellet sample was located between two Pt plates and a symmetrical metal/polymer/metal configuration (platinum/polymer/platinum) was used. The area of the Pt plates was $0.8 \mathrm{~cm}^{2}$.

The electrical characterization of dry polymers at room temperature was also carried out placing a drop of mercury on a $\mathrm{PPy} / \mathrm{PW}_{12} \mathrm{O}_{40}{ }^{3-}$ film electrosynthesized on stainless steel plate using in this case an asymmetrical metal/polymer/metal configuration (mercury/polymer/stainless steel) [2,33]. The area of the PPy/ $\mathrm{PW}_{12} \mathrm{O}_{40}{ }^{3-}$ film/stainless was $0.8 \mathrm{~cm}^{2}$.

The electrochemical characterization of polymer/stainless steel systems immersed in electrolytic solutions was carried out by impedance spectroscopy (EIS), adopting a standard three-electrode configuration [10]. The working electrode was the stainless steel sample coated with the researched polypyrrole $/ \mathrm{PW}_{12} \mathrm{O}_{40}{ }^{3-}$ film. The reference and the counter-electrode were a saturated calomel electrode (SCE) and a large size graphite sheet, respectively. The area of the PPy $/ \mathrm{PW}_{12} \mathrm{O}_{40}{ }^{3-}$ film/stainless was $0.8 \mathrm{~cm}^{2}$. 
The electrochemical characterization of the polypyrrole/ $\mathrm{PW}_{12} \mathrm{O}_{40}{ }^{3-}$ membranes was performed by impedance spectroscopy (EIS), adopting a four electrodes configuration [10]. In this set-up, the polypyrrole/ $/ \mathrm{PW}_{12} \mathrm{O}_{40}{ }^{3-}$ membrane was clamped between two identical chambers into a Hittorf cell. On both sides of the membrane the chambers were filled with identical volume of electrolytic solution at the same concentration. Two electrodes were introduced in each one of the chambers, consisting in a saturated calomel electrode (SCE) used as reference electrode and a platinum electrode as secondary electrode, completing in this way the four electrodes symmetric set-up. The area of the $\mathrm{PPy} / \mathrm{PW}_{12} \mathrm{O}_{40}{ }^{3-}$ membrane was $0.8 \mathrm{~cm}^{2}$.

Different solutions were employed to study the electrochemical behavior of the films: 1) The influence of the concentration of the salt in the EIS spectra was determined by using different concentrations of $\mathrm{NaCl}\left(10^{-1}, 5 \cdot 10^{-2}, 10^{-2}, 5 \cdot 10^{-3}\right)$.

2) Two cations of very different size were employed to observe the influence of this parameter in the EIS spectra. Solutions of the chloride salts of $\mathrm{Na}^{+}$and $(\mathrm{n}-\mathrm{Me})_{4} \mathrm{~N}^{+}$were employed.

3) The influence of strong acid and strong basic solutions was studied by using two different solutions: $0.5 \mathrm{M} \mathrm{H}_{2} \mathrm{SO}_{4}(\mathrm{pH} \sim 0)$ and $0.1 \mathrm{M} \mathrm{NaOH}+0.1 \mathrm{M} \mathrm{Na}_{2} \mathrm{SO}_{4}(\mathrm{pH} \sim 13)$ To analyze quantitatively the behavior of the films investigated, the experimental results were fitted using a non-linear least squares fitting minimization method by ZView software (version 2.7).

2.4. Cyclic voltammetry measurements 
Cyclic voltammetry (CV) measurements of polypyrrole free-standing films were performed with an Autolab PGSTAT302 potentiostat/galvanostat. A four-electrode arrangement with two $\mathrm{Ag} / \mathrm{AgCl}(3 \mathrm{M} \mathrm{KCl})$ reference electrodes and two stainless steels rods was employed.

2.5. Scanning electron microscopy and energy dispersive X-ray characterization A Jeol JSM-6300 scanning electron microscope was employed to observe the morphology of the samples and perform EDX measurements. SEM analyses were performed using an acceleration voltage of $20 \mathrm{kV}$. EDX measurements were obtained between 0 and $20 \mathrm{keV}$.

\subsection{FTIR-ATR spectroscopy}

Fourier transform infrared spectroscopy with horizontal multirebound attenuated total reflection (FTIR-ATR) was performed with a Nicolet Magna 550 Spectrometer equipped with DTGS detector. An accessory with pressure control was employed to equalize the pressure in the different solid samples. A prism of $\mathrm{ZnSe}$ was employed. Spectra were collected with a resolution of $4 \mathrm{~cm}^{-1}$, and 100 scans were averaged for each sample.

\section{Results and discussion}

3.1. Electrochemical synthesis of polypyrrole/ $/ \mathrm{PW}_{12} \mathrm{O}_{40}{ }^{3-}$ on stainless steel Fig. 1 shows the current density transient curve for the potentiostatic synthesis of $\mathrm{PPy} / \mathrm{PW}_{12} \mathrm{O}_{40}{ }^{3-}$ on stainless steel. It can be seen that in the first stage the current density 
grows until reaches a maximum, and then decreases slowly until a nearly constant value is reached. In this electrosynthesis, $0.5 \mathrm{C} \mathrm{cm}^{-2}$ of electrosynthesis charge were achieved. The thickness (e) of the electrosynthesized hybrid material was estimated from the following equation [34]:

$$
\mathrm{e}=\mathrm{Q}\left(\mathrm{M}_{\mathrm{Py}}+(\mathrm{y} / 3) \mathrm{M}_{\mathrm{POM}}\right) /(\rho \mathrm{F}(2+\mathrm{y}))
$$

Where $Q$ is the consumed electrical quantity per unit area used with a coulombic efficiency of $50 \%$ (obtained comparing consumed charge and mass of several hybrid material specimens). $M_{P y}$ and $M_{P O M}$ are respectively the masses of a pyrrole repeating unit in the polymer (loss of $2 \mathrm{H}^{+}$per pyrrole ring) and the counter-ion $\mathrm{PW}_{12} \mathrm{O}_{40}{ }^{3-} ; 65$ and $2877 \mathrm{~g} \mathrm{~mol}^{-1}$ respectively. $y$ is the doping ratio estimated by X-ray photoelectron spectroscopy (XPS) analyses $\left(\mathrm{N}^{+} / \mathrm{N}\right.$ atomic ratio) (0.5) [33]. $\rho$ is the hybrid material density, $2.95 \mathrm{~g} \mathrm{~cm}^{-3}$ [35]; and $F$ is the Faraday constant $\left(96485 \mathrm{C} \mathrm{mol}^{-1}\right)$. The calculated thickness of the film obtained was approximately $3.8 \mu \mathrm{m}$.

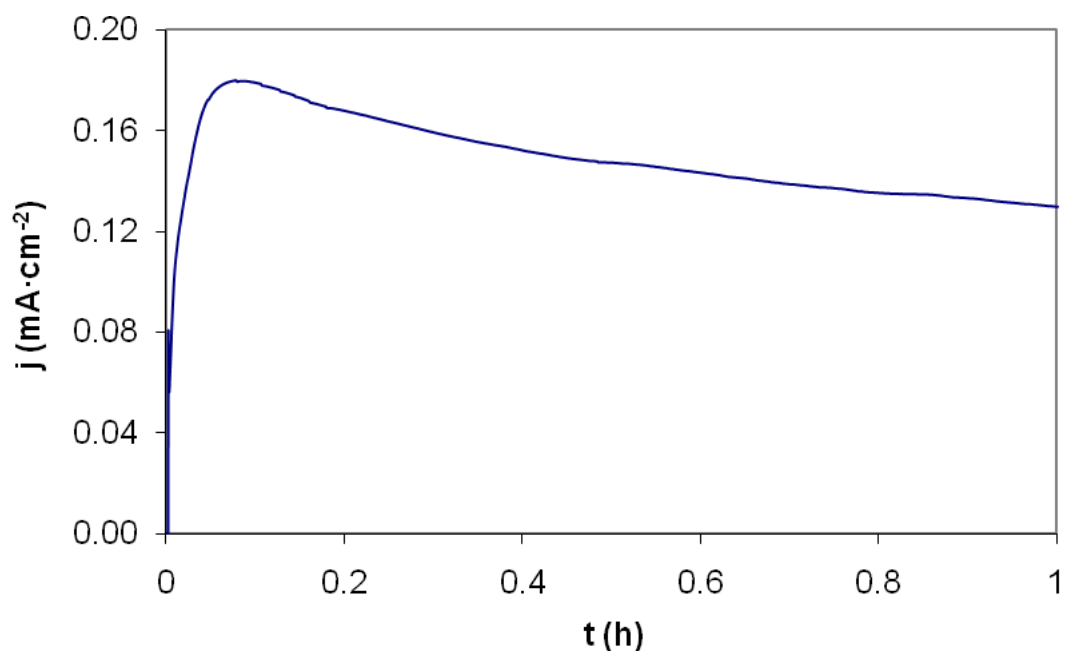

Fig. 1. Current transient curve for potentiostatic synthesis of $\mathrm{PPy} / \mathrm{PW}_{12} \mathrm{O}_{4}{ }^{3-}$ on stainless steel. Acetonitrile medium, $0.01 \mathrm{M} \mathrm{H}_{3} \mathrm{PW}_{12} \mathrm{O}_{40}, 0.2 \mathrm{M}$ pyrrole. Start potential: $-0.289 \mathrm{~V}$, synthesis potential: $+0.86 \mathrm{~V}, \mathrm{Q}=0.5 \mathrm{C} \mathrm{cm}^{-2}$. 
3.2. Electrochemical impedance spectroscopy characterization with temperature Electrochemical impedance spectroscopy measurements with temperature showed that as the temperature increased, the impedance modulus lowered in the Bode plots. The phase angle obtained at the different temperatures was mainly $0^{\circ}$. This value of phase angle indicates that the material acts as a resistor. The equivalent circuit employed to adjust the data values was a single resistance $(\mathrm{R})$. The data were adjusted with the Zview software and the resistance of the film at the different temperatures was obtained. The electrical conductivity $\left(\mathrm{S} \mathrm{cm}^{-1}\right)$ of the film at the different temperatures was calculated with the data of resistance obtained previously, thickness of the film $(3.8$ $\mu \mathrm{m})$ and measured area $\left(0.8 \mathrm{~cm}^{2}\right)$. The electrical conducitivity of the $\mathrm{PPy} / \mathrm{PW}_{12} \mathrm{O}_{40}{ }^{3-}$ film increases with temperature as it was commented before. In general, the electrical conductivity of conducting polymers increases with the increase of temperature (semiconducting nature), as thermal excitation is needed to move charge carriers [36]. The opposite behavior (metallic conduction) only has been reported in ordered polyaniline [37]. The electrical conductivity behavior with temperature of conducting polymers can be explained using different models. In this work we have applied the Arrhenius model [38-40] (1).

$$
\sigma=\sigma_{0} \exp \left[-\frac{E_{a}}{k T}\right]
$$

Where $\sigma$ is the conductivity $\left(\mathrm{S} \mathrm{cm}^{-1}\right)$ at each temperature, $\sigma_{0}$ is the conductivity at room temperature, $E_{a}(\mathrm{eV})$ is the carrier activation energy, $k$ is the Boltzmann constant $\left(8.61734 \cdot 10^{5} \mathrm{eV} \mathrm{K}^{-1}\right)$ and $T$ is the temperature $(\mathrm{K})$. The plot of $\operatorname{Ln}(\sigma) \mathrm{vs} 1000 / \mathrm{T}$ is shown in Fig. 2. It can be seen that the representation of these data gives a straight line, so the data adjust to the Arrhenius model. The slope of the adjust is equal to $\mathrm{E}_{\mathrm{a}} / 1000 \mathrm{k}$, 
so the activation energy can be calculated from the value of the slope obtained by the linear adjust. The activation energy obtained was $170 \mathrm{meV}$; similar values have been obtained in bibliography for polypyrrole pellets obtained by chemical polymerization [38]. In an our previous work [18] we synthetized chemically $\mathrm{PPy} / \mathrm{PW}_{12} \mathrm{O}_{40}{ }^{3-}$ on polyester fabrics. A value of $44.4 \mathrm{meV}$ was obtained for the activation energy. The tittle difference between these two values could be due to the synthesis procedure and the substrate. In the present article, we obtained free-standing films of PPy/ $\mathrm{PW}_{12} \mathrm{O}_{40}{ }^{3-}$. In the previous article, the $\mathrm{PPy} / \mathrm{PW}_{12} \mathrm{O}_{40}{ }^{3-}$ polymer was obtained on polyester fabric. In addition, in the previous article the $\mathrm{PPy} / \mathrm{PW}_{12} \mathrm{O}_{40}{ }^{3-}$ film was chemically synthesised, while in the present work the free-standing film was obtained electrochemically and on an stainless steel plate. In the present article, we used electrosynthesized PPy/PW $12 \mathrm{O}_{40}{ }^{3-}$ films due to their higher electrical properties as we dicussed in a previous article [19]. $\mathrm{PPy} / \mathrm{PW}_{12} \mathrm{O}_{40}{ }^{3-}$ electrochemically synthesized films showed by cyclic voltammetry experiments better electroactivity. The surface resistivity for these films was 17-20 $\Omega /$ square in comparison with $400-500 \Omega /$ square for chemically synthesized ones.

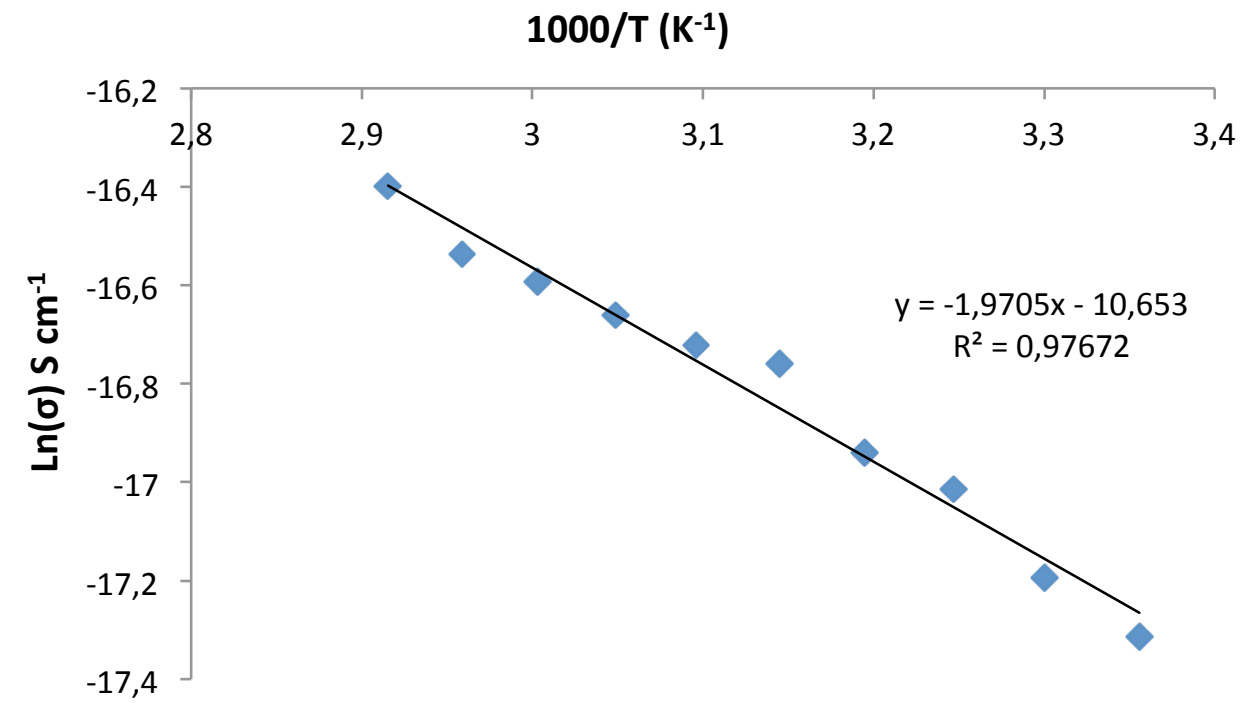


Fig. 2. Plot of $\operatorname{Ln}(\sigma)$ vs. $1000 / \mathrm{T}$ for the film of $\mathrm{PPy} / \mathrm{PW}_{12} \mathrm{O}_{40}{ }^{3-}$.

3.3. Impedance response of $\mathrm{PPy} / \mathrm{PW}_{12} \mathrm{O}_{40}{ }^{3-}$ free-standing films in $\mathrm{NaCl}$ solutions of different concentration

When a free-standing film is placed in symmetrical configuration between two ionic solutions and an ac voltage is applied, the electrical response is due to the following phenomena:

- Rs: electrolyte resistance.

- Ws: diffusion of counter-ions in bulk polymeric film. Ws-R: Diffusion resistance. Ws$\mathrm{T}: 1^{2} / \mathrm{D}(\mathrm{s}), 1$ : length of the diffusion layer, $\mathrm{D}$ : binary electron-ion diffusion coefficient. Ws-P: Warburg exponent.

- Wredox: diffusion of redox species from solution to polymeric film.

- Rredox: interfacial charge transfer resistance of redox species between polymeric film and solution.

- Credox: interfacial capacitance associated in parallel with Rredox. Wredox, Rredox and Credox are negligible since there are not redox couples in solution $\left(\mathrm{Na}^{+}, \mathrm{Cl}^{-}\right)$.

- $\mathrm{Rf} / \mathrm{s}$ : ionic exchange resistance between solution and $\mathrm{PPy} / \mathrm{PW}_{12} \mathrm{O}_{40}{ }^{3-}$ membrane.

- Cf/s: capacitance associated with the interface PPy/PW ${ }_{12} \mathrm{O}_{40}{ }^{3-}$ membrane/solution where the ionic exchange occurs.

Taking into account the physical phenomena commented before, and the bibliography about polypyrrole free-standing films [7-13,41], the electrical circuit proposed to analyze the impedance response is showed in Fig. 3. 


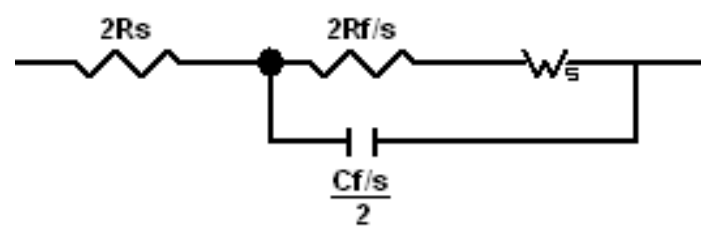

Fig. 3. Electrical circuit for free-standing films in symmetrical configuration solution/membrane/solution

To study the electric properties of the $\mathrm{PPy} / \mathrm{PW}_{12} \mathrm{O}_{40}{ }^{3-}$ membranes in relation to electrolyte concentration, four different $\mathrm{NaCl}$ solutions were prepared with the following concentrations: $0.1,0.05,0.01$ and $0.005 \mathrm{M}$. Fig. 4. shows the Nyquist plot for a $\mathrm{PPy} / \mathrm{PW}_{12} \mathrm{O}_{40}{ }^{3-}$ membrane immersed in symmetrical configuration in $0.1 \mathrm{M} \mathrm{NaCl}$ solution. Two loops appeared in the diagram due to two relaxation processes. The first loop at high-middle frequencies is related to the ionic exchange between $\mathrm{PPy} / \mathrm{PW}_{12} \mathrm{O}_{40}{ }^{3-}$ membrane and the solution. The diagram shows a second loop at low frequencies. This time constant is due to the counter-ion diffusion in the bulk polymeric film. This diffusion presented transmissive boundary conditions, since a resistive behavior at very low frequencies is shown in the Nyquist plot. Experimental data were very close to fitting data, with an error less than $4 \%$. 


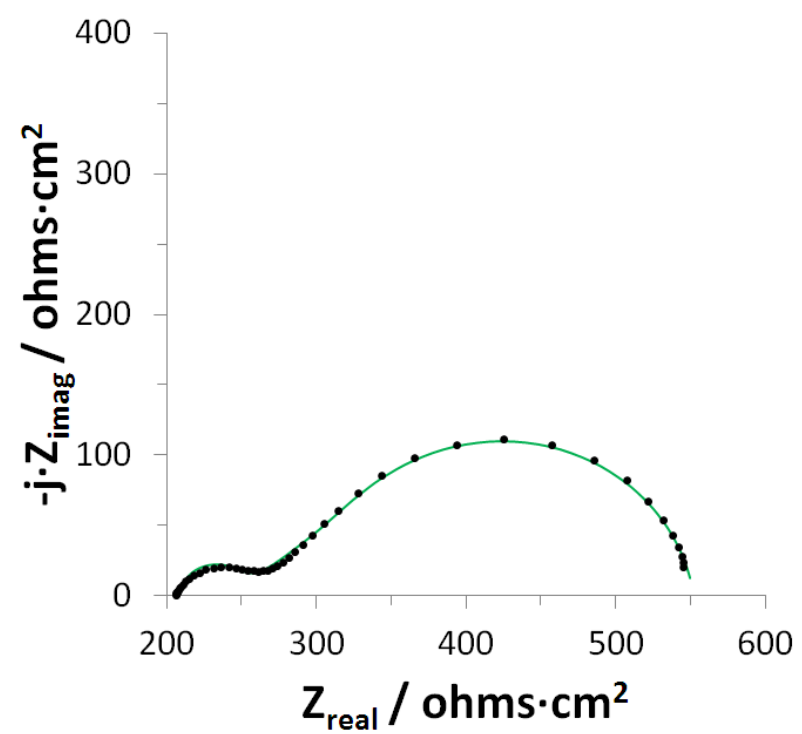

Fig. 4. Nyquist plot for $\mathrm{PPy} / \mathrm{PW}_{12} \mathrm{O}_{40}{ }^{3-}$ membrane in $0.1 \mathrm{M} \mathrm{NaCl}$ solution. Exposed electrode area: $1 \mathrm{~cm}^{2}$. Frequency range from $10^{4}$ to $10^{-2} \mathrm{~Hz} \cdot \bullet$ Experimental data. Fitting data.

Fig. 5 shows the Bode plots for $\mathrm{PPy} / \mathrm{PW}_{12} \mathrm{O}_{40}{ }^{3-}$ membranes that were immersed in $\mathrm{NaCl}$ solutions with different concentrations: $0.1,0.05,0.01$ and $0.005 \mathrm{M}$. Nyquist plots are not shown because the shape was very similar to Fig. 4 . Two time constants can be appreciated in the plot phase vs. frequency for all the assays. The high-middle frequency range (10000-10 Hz) corresponds to the ionic exchange between membrane and solution, as it was commented before. This time constant changed to lower frequencies when the $\mathrm{NaCl}$ solution was more diluted. The middle-low frequency range $(10-0.01 \mathrm{~Hz})$ is due to diffusion of counter-ions in the polymeric membrane. Also in this case, the time constant changed to lower frequencies when the $\mathrm{NaCl}$ solution was more diluted. Seeing the impedance modulus vs. frequency plot, the impedance modulus increased when the membrane was immersed in more diluted solutions for all the frequencies analyzed. Therefore, the two relaxation processes (ionic exchange and 
diffusion) were slower when the $\mathrm{NaCl}$ concentration was lower. These facts can be checked in Table 1 where the fitting data were obtained taking into account the electrical circuit of Fig. 3. The ionic exchange resistance $(\mathrm{Rf} / \mathrm{s})$ increased when the $\mathrm{PPy} / \mathrm{PW}_{12} \mathrm{O}_{40}{ }^{3-}$ membranes were immersed in $\mathrm{NaCl}$ solutions more diluted. Capacitance values were slightly higher for more concentrated solutions. The diffusion resistance (Ws-R) of counter-ions increased when the polymeric membranes were immersed in solutions more diluted. Obviously, the electrolyte resistance increased when the concentration of $\mathrm{NaCl}$ decreased.

To analyze the effect of the size of counter-ions, the PPy/PW ${ }_{12} \mathrm{O}_{40}{ }^{3-}$ membrane was immersed in $0.1 \mathrm{M}\left(\mathrm{CH}_{3}\right)_{4} \mathrm{~N}^{+}$solution. $\mathrm{PPy} / \mathrm{PW}_{12} \mathrm{O}_{40}{ }^{3-}$ membrane mainly exchanges cations with the electrolyte since $\mathrm{PW}_{12} \mathrm{O}_{40}{ }^{3-}$ is a great anion entrapped within the polymeric matrix [1]. Table 1 shows how both ionic exchange resistance and diffusion resistance increased significantly for $0.1 \mathrm{M}\left(\mathrm{CH}_{3}\right)_{4} \mathrm{~N}^{+}$solution in comparison to $0.1 \mathrm{M}$ $\mathrm{NaCl}$ one. 

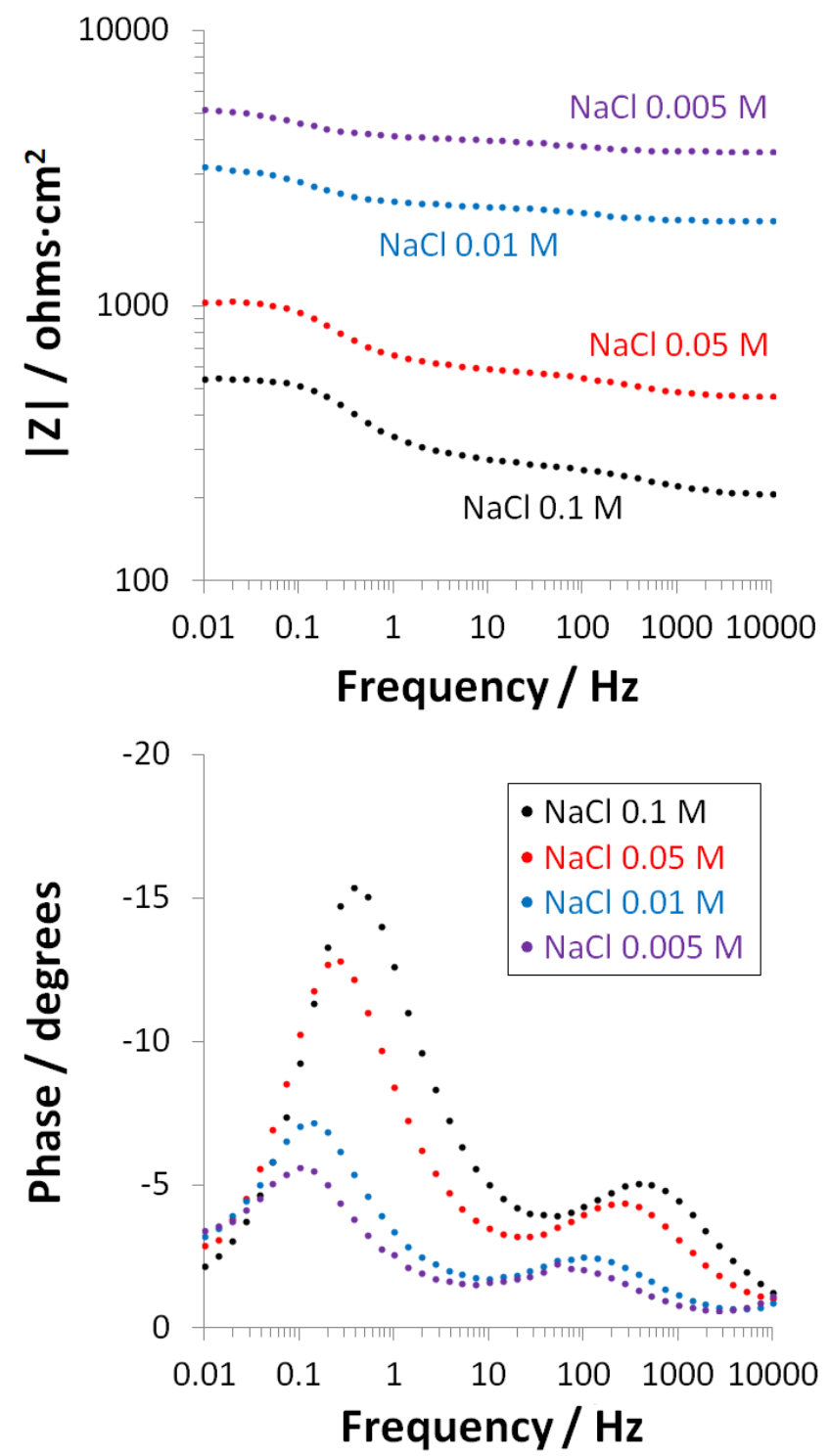

Fig. 5. Bode plots for $\mathrm{PPy} / \mathrm{PW}_{12} \mathrm{O}_{40}{ }^{3-}$ membranes in different $\mathrm{NaCl}$ solutions. Exposed electrode area: $1 \mathrm{~cm}^{2}$. Frequency range from $10^{4}$ to $10^{-2} \mathrm{~Hz}$. 
Table 1. Results of the fitting of impedance data of $\mathrm{PPy} / \mathrm{PW}_{12} \mathrm{O}_{40}{ }^{3-}$ membranes in different solutions. Exposed electrode area: $1 \mathrm{~cm}^{2}$. Frequency range from $10^{4}$ to $10^{-2} \mathrm{~Hz}$.

\begin{tabular}{|lccccc|}
\hline $\begin{array}{c}\mathrm{PPy} / \mathrm{PW}_{12} \mathrm{O}_{40}{ }^{3-} \\
\text { membranes }\end{array}$ & $\begin{array}{c}\mathrm{NaCl} \\
0.1 \mathrm{M}\end{array}$ & $\begin{array}{c}\mathrm{NaCl} \\
0.05 \mathrm{M}\end{array}$ & $\begin{array}{c}\mathrm{NaCl} \\
0.01 \mathrm{M}\end{array}$ & $\begin{array}{c}\mathrm{NaCl} \\
0.005 \mathrm{M}\end{array}$ & $\begin{array}{c}\left(\mathrm{CH}_{3}\right)_{4} \mathrm{~N}^{+} \\
0.1 \mathrm{M}\end{array}$ \\
\hline $\mathrm{Rs}\left(\Omega \cdot \mathrm{cm}^{2}\right)$ & 105 & 237 & 1022 & 1837 & 98 \\
$\mathrm{Rf} / \mathrm{s}\left(\Omega \cdot \mathrm{cm}^{2}\right)$ & 20 & 39 & 88 & 124 & 128 \\
$\mathrm{Cf} / \mathrm{s}\left(\mathrm{F} / \mathrm{cm}^{2}\right)$ & $1.27 \cdot 10^{-5}$ & $1.10 \cdot 10^{-5}$ & $0.92 \cdot 10^{-5}$ & $0.88 \cdot 10^{-5}$ & $0.4 \cdot 10^{-5}$ \\
$\mathrm{Ws}-\mathrm{R}\left(\Omega \cdot \mathrm{cm}^{2}\right)$ & 303 & 506 & 1025 & 1452 & 15970 \\
Ws-T $(\mathrm{s})$ & 1.7 & 2.6 & 5.4 & 8.0 & 17.0 \\
Ws-P & 0.5 & 0.5 & 0.4 & 0.4 & 0.4 \\
\hline
\end{tabular}

\subsection{Voltammetry measurements: ionic dc conductivity}

Voltammetry of the polypyrrole free-standing film was performed in the 4-electrode arrangement. The measurements were done in $0.5 \mathrm{M} \mathrm{H}_{2} \mathrm{SO}_{4}$ and the potential range ($0.2 \mathrm{~V},+1 \mathrm{~V}$ ) was employed. The same measurements were done by using the same configuration but removing the polypyrrole film. With the latter experiments the resistance of the experimental arrangement was measured. This resistance is determined by the configuration of the electrodes and the resistance of the electrolyte employed. Fig. 6 shows the CV measurements for the system with and without the polypyrrole free-standing film. As can be seen, the experiments show an ohmic behavior. From the slope of the blue line (without membrane), the resistance of the arrangement can be calculated, which was about $7.1 \Omega \cdot \mathrm{cm}^{2}$. Black line in Fig. 6 shows the voltammogram for the system with the polypyrrole film; as it can be observed, it presented also an ohmic behavior. In this case, the resistance obtained was $29.7 \Omega \cdot \mathrm{cm}^{2}$. The resistance due only to the membrane is the difference between $29.7 \Omega \cdot \mathrm{cm}^{2}$ and $7.1 \Omega \cdot \mathrm{cm}^{2}, 22.6$ 
$\Omega \cdot \mathrm{cm}^{2}$. Taking into account equation (2) and the thickness of the membrane $(3.8 \mu \mathrm{m})$, the ionic de conductivity of the PPy/ $\mathrm{PW}_{12} \mathrm{O}_{40}{ }^{3-}$ membrane was: $1.7 \cdot 10^{-5} \mathrm{~S} \cdot \mathrm{cm}^{-1}$.

$$
\sigma=\frac{\mathrm{j} \cdot \mathrm{d}}{\Delta \varphi M}
$$

Where $\sigma$ is the ionic de conductivity, $j$ the current density, $d$ the thickness of the membrane and $\Delta \varphi_{M}$ the potential drop across the membrane.

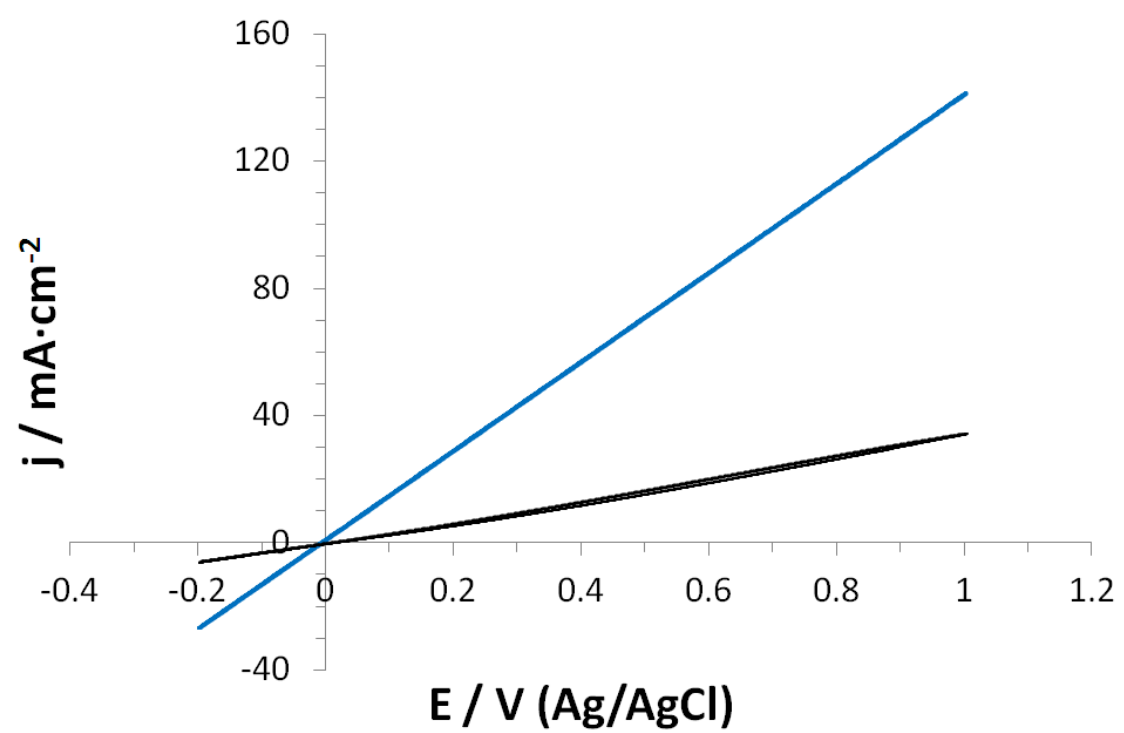

Fig. 6. Cyclic voltammograms obtained in a 4-electrode arrangement in $0.5 \mathrm{M} \mathrm{H}_{2} \mathrm{SO}_{4}$ solution; scan rate: $50 \mathrm{mV} \cdot \mathrm{s}^{-1}$. - Without $\mathrm{PPy} / \mathrm{PW}_{12} \mathrm{O}_{40}{ }^{3-}$ membrane; - with $\mathrm{PPy} / \mathrm{PW}_{12} \mathrm{O}_{40}{ }^{3-}$ membrane.

\subsection{SEM and EDX measurements}

Fig. 7 presents different micrographs as well as the corresponding EDX spectra of films of PPy/ $\mathrm{PW}_{12} \mathrm{O}_{40}{ }^{3-}$. The films were detached from stainless steels plates and Fig 7-a shows the morphology of the surface directly in contact with the metallic surface. Fig. 
7-c shows the morphology of the surface in contact with the electrolytic solution during the electrosynthesis. The film of Fig. 7-a presents a smooth surface with the presence of some tubules. This surface was in contact with the metallic surface and that is why presents this morphology. The surface of the film that was not in contact with the metal can be observed in Fig. 7-c and as it can be observed, it presents globular morphology. Fig. 7-a shows the EDX spectrum in the zone indicated in the attached micrograph. It is noticeable the presence of different bands attributed to $\mathrm{W}$, arising from the counter-ion $\left(\mathrm{PW}_{12} \mathrm{O}_{40}{ }^{3-}\right)$.

Fig. 7-b and 7-c show the EDX spectrum for the $\mathrm{PPy} / \mathrm{PW}_{12} \mathrm{O}_{40}{ }^{3-}$ film after treatment in basic solution ( $\mathrm{pH} 13)$. As it can be observed, $\mathrm{W}$ is no longer detected. The counter-ion has been decomposed and expulsed from the polymer matrix. $\mathrm{PW}_{12} \mathrm{O}_{40}{ }^{3-}$ suffers a decomposition reaction into $\mathrm{PO}_{4}{ }^{3-}$ and $\mathrm{WO}_{4}{ }^{2-}$ at $\mathrm{pH}>8.3$ [42]. It can also be noticed the appearance of $\mathrm{Na}$ and $\mathrm{S}$ peaks, indicating that $\mathrm{SO}_{4}{ }^{2-}$ and $\mathrm{Na}^{+}$arising from the $\mathrm{pH} 13$ solution $\left(\mathrm{NaOH} 0.1 \mathrm{M}\right.$ and $\left.\mathrm{Na}_{2} \mathrm{SO}_{4} 0.1 \mathrm{M}\right)$ have been incorporated into the polymer matrix. The decomposition of the $\mathrm{PW}_{12} \mathrm{O}_{40}{ }^{3-}$ would cause the apparition of a more porous structure with channels. These channels cannot be observed by means of SEM with higher magnification. We have to take into account that the size of this counter-ion is approximately $10 \AA[43]$, so it is difficult to observe these channels. 

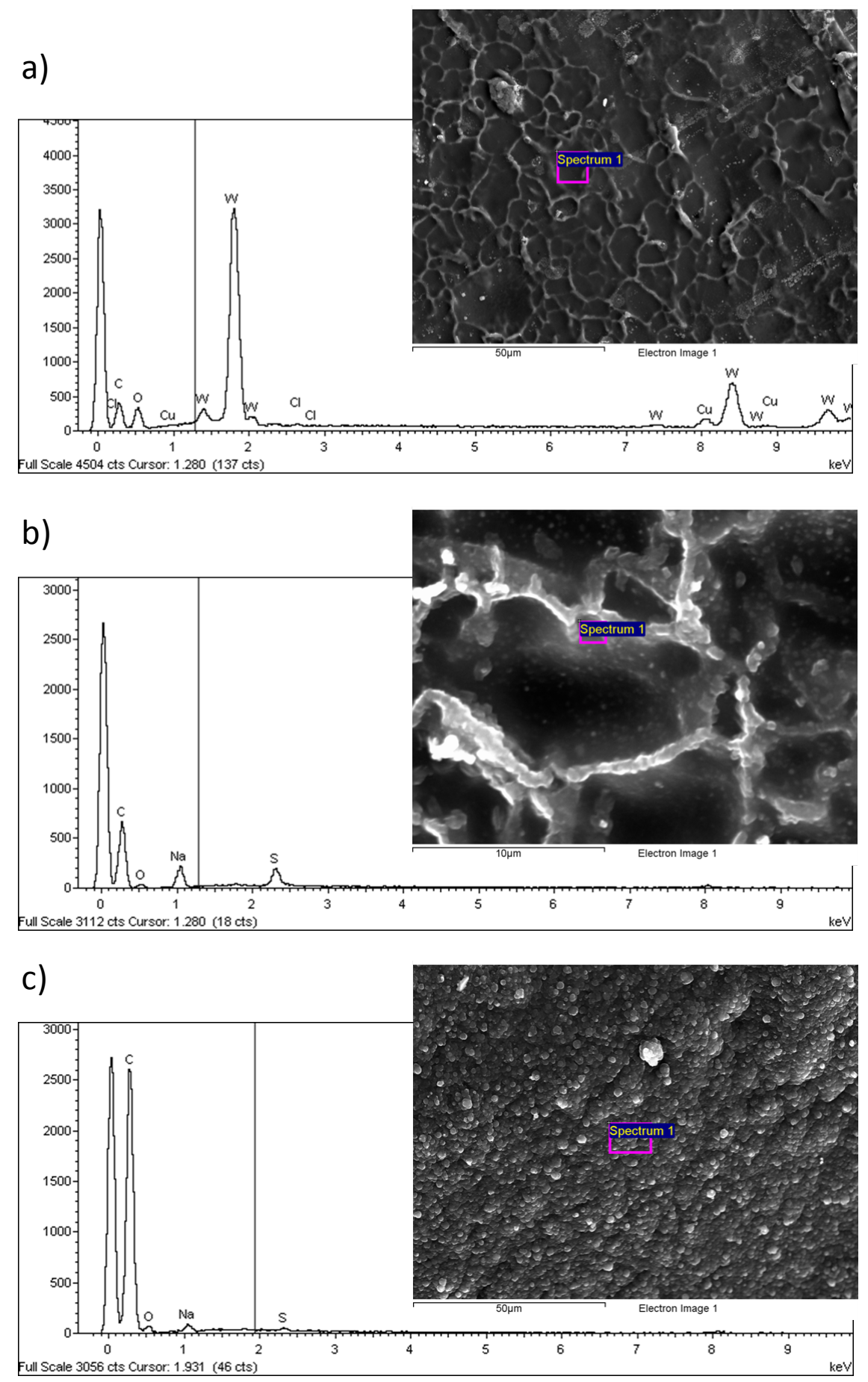

Fig. 7. EDX spectra and micrographs of: (a) $\mathrm{PPy} / \mathrm{PW}_{12} \mathrm{O}_{40}{ }^{3-}$, (b) and (c) $\mathrm{PPy} / / \mathrm{PW}_{12} \mathrm{O}_{40}{ }^{3-}$ $+1 \mathrm{~h}$ contact with $\mathrm{pH} 13$ solution.

\subsection{FTIR-ATR spectroscopy}


Fig. 8 compares the spectra for the film of PPy/PW ${ }_{12} \mathrm{O}_{40}{ }^{3-}$ and the film treated during 1 $\mathrm{h}$ in the $\mathrm{pH} 13$ solution. When the sample is soaked during $1 \mathrm{~h}$ in the $\mathrm{pH} 13$ solution, the $\mathrm{PW}_{12} \mathrm{O}_{40}{ }^{3-}$ decomposes and it is removed from the polypyrrole structure as it was commented previously. The comparison of both spectra, allows the assignation of the bands attributed to polypyrrole (present in both spectra) and to the counter-ion (present only in the $\mathrm{PPy} / \mathrm{PW}_{12} \mathrm{O}_{40}{ }^{3-}$ spectrum). In the spectrum of PPy/PW ${ }_{12} \mathrm{O}_{40}{ }^{3-}$, different bands attributed to polypyrrole could be observed, such as: bands around $1500 \mathrm{~cm}^{-1}$ assigned to $\mathrm{C}=\mathrm{C}$ stretching vibration and the bands around $1427 \mathrm{~cm}^{-1}$ could be assigned to $\mathrm{C}-\mathrm{C}$ stretching vibration $[44,45]$. The bands around 1030 and 1140 were attributed to bending vibration of polypyrrole $[44,45]$. The band around $1270 \mathrm{~cm}^{-1}$ was assigned to C-N stretching $[44,45]$. Another band at $871 \mathrm{~cm}^{-1}$ was assigned to $=\mathrm{C}-\mathrm{H}$ in plane vibration [46]. Two bands can be assigned to the counter-ion: 963 and $1070 \mathrm{~cm}^{-1}$. The band around $1070 \mathrm{~cm}^{-1}$ is attributed to P-O stretching vibration [47-49]. Another band assigned to W-O stretching vibration could also be observed at $963 \mathrm{~cm}^{-1}[48,49]$. The treatment with the $\mathrm{pH} 13$ solution showed the elimination of the bands attributed to the counter-ion $\left(1070\right.$ and $\left.963 \mathrm{~cm}^{-1}\right)$. The bands attributed to polypyrrole showed small shifts in the wavenumbers due to the basic treatment. The results obtained by FTIR confirm the removal of the counter-ion as EDX analyses also showed. 


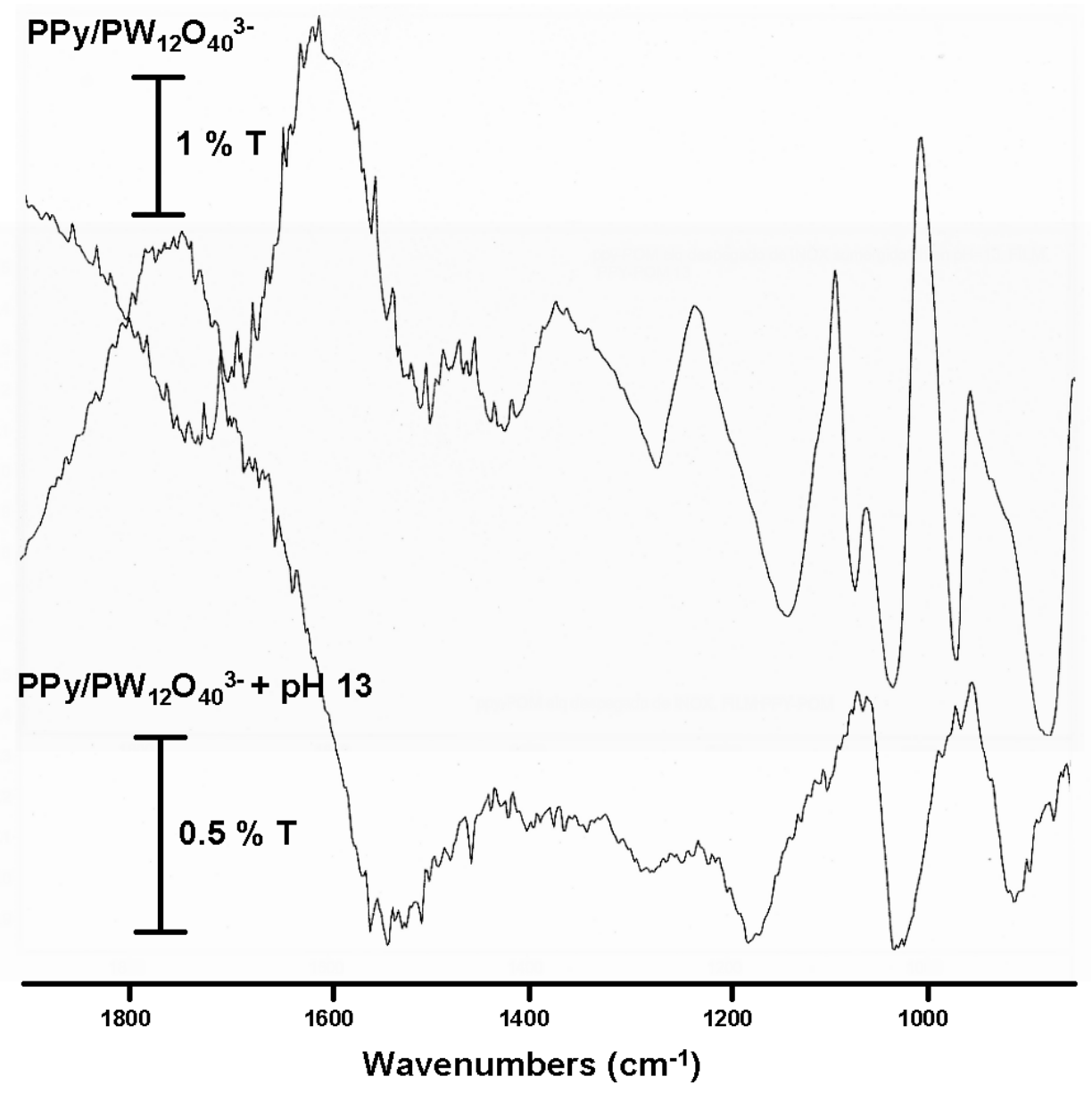

Fig. 8. FTIR-ATR spectrum of PPy/PW ${ }_{12} \mathrm{O}_{40}{ }^{3-}$ and $\mathrm{PPy} / \mathrm{PW}_{12} \mathrm{O}_{40}{ }^{3-}+1 \mathrm{~h} \mathrm{pH} 13$. Resolution $4 \mathrm{~cm}^{-1}, 100$ scans.

\subsection{EIS response in asymmetric configuration metal/polypyrrole/solution}

Fig. 9 shows the Nyquist plots for symmetric configurations (ionic and electronic pathway) and asymmetric one. The first loop at high-middle frequencies (on the left) for $0.5 \mathrm{M} \mathrm{H}_{2} \mathrm{SO}_{4} / \mathrm{PPy} / 0.5 \mathrm{M} \mathrm{H}_{2} \mathrm{SO}_{4}$ configuration was quite similar to the first loop for metal/PPy/0.5 $\mathrm{M} \mathrm{H}_{2} \mathrm{SO}_{4}$ configuration. On the contrary, the loop for metal/PPy/metal configuration was very different (very greater size) in comparison to metal/PPy/0.5 M $\mathrm{H}_{2} \mathrm{SO}_{4}$ one. Therefore, the fist loop for asymmetric configuration can be associated to the ionic pathway. The second loop at lower frequencies (on the right) for $0.5 \mathrm{M}$ 
$\mathrm{H}_{2} \mathrm{SO}_{4} / \mathrm{PPy} / 0.5 \mathrm{M} \mathrm{H}_{2} \mathrm{SO}_{4}$ was due to the diffusion of counter-ions in the bulk polymeric film, as it was commented in previous section (see Fig. 4). This diffusion was characterized by transmissive boundary conditions. However, the metal//PPy/0.5 M $\mathrm{H}_{2} \mathrm{SO}_{4}$ configuration showed at low frequencies diffusion by reflective boundary conditions (capacitive behavior at very low frequencies). Taking into account these comments, a similar electrical circuit to Fig. 3 one was proposed to model the asymmetric configuration. In this case, Warburg diffusion with reflective boundary conditions was used.

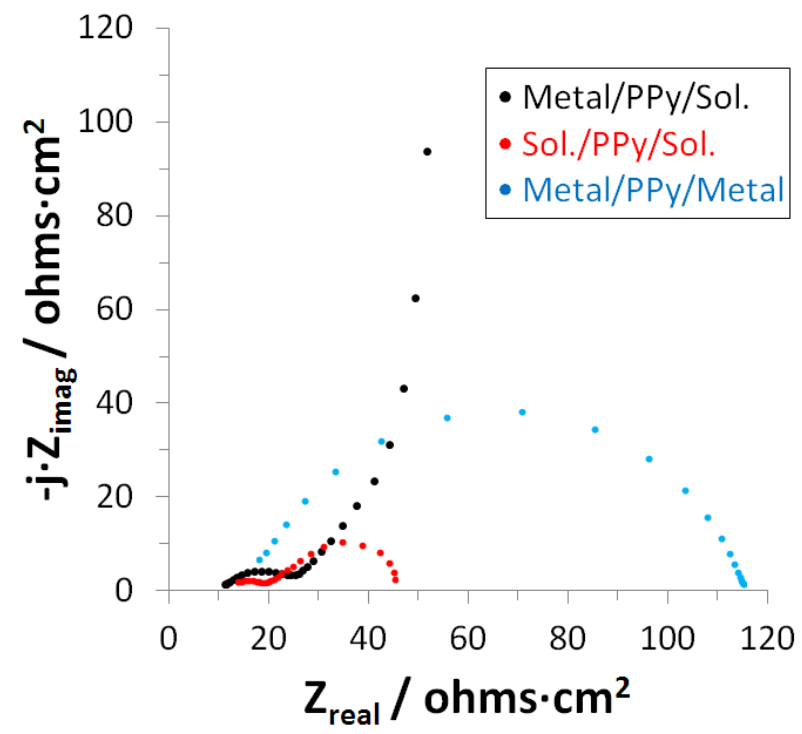

Fig. 9. Nyquist plots for $\mathrm{PPy} / \mathrm{PW}_{12} \mathrm{O}_{40}{ }^{3-}$ films in different configurations: • Metal/PPy/0.5 M H $\mathrm{SO}_{4} ; \bullet 0.5 \mathrm{M} \mathrm{H}_{2} \mathrm{SO}_{4} / \mathrm{PPy} / 0.5 \mathrm{M} \mathrm{H}_{2} \mathrm{SO}_{4} ; \bullet$ Metal/PPy/Metal. Exposed electrode area: $1 \mathrm{~cm}^{2}$. Frequency range from $10^{4}$ to $10^{-2} \mathrm{~Hz}$.

The impedance response for stainless steel coated by $\mathrm{PPy} / \mathrm{PW}_{12} \mathrm{O}_{40}{ }^{3-}$ immersed in $0.1 \mathrm{M}$ $\mathrm{NaOH}+0.1 \mathrm{M} \mathrm{Na}_{2} \mathrm{SO}_{4}(\mathrm{pH} \sim 13)$ solution was very different. Fig. 10 shows the Bode plot for symmetric and asymmetric configurations. Two relaxations appeared in the 
asymmetric configuration. These two relaxations presented time constants very different to the symmetric configuration ones. In this case, ionic transfer resistance and electronic resistance could not be attributed to the relaxations in asymmetric configuration. Previous sections indicated how $\mathrm{PW}_{12} \mathrm{O}_{40}{ }^{3-}$ suffers decomposition (EDX and FTIR analysis) at $\mathrm{pH} \sim 13$. In this way, PPy matrix presents a very porous structure. Our previous paper [33] treated about corrosion protection in carbon steels coated by $\mathrm{PPy} / \mathrm{PW}_{12} \mathrm{O}_{40}{ }^{3-}$. The solution used was $0.05 \mathrm{M} \mathrm{NaOH}$. Electrode material and solution was similar to the present work. Taking into account that research, the electrical circuit proposed is shown in Fig. 11. In this case, $R s$ corresponds to the electrolyte resistance + ion-ion exchange resistance + electronic resistance. Roxide and Coxide are the resistance and capacitance due to the layer of $\mathrm{Fe}$ and $\mathrm{Cr}$ oxides placed between the stainless steel and the $\mathrm{PPy} / \mathrm{PW}_{12} \mathrm{O}_{40}{ }^{3-}$ polymer. Rtc and $C d l$ are the resistance and capacitance due to the stainless steel/electrolyte interface at the base of the pores of the Fe and $\mathrm{Cr}$ oxide layer, related to the charge transfer reaction of the stainless steel corrosion. Table 2 shows the results of the fitting for metal/PPy/solution configuration at $\mathrm{pH} \sim 0$ and $\mathrm{pH} \sim 13$. The electrical phenomena were very different for these two systems. At $\mathrm{pH} 13$, the electrical response obtained is mainly due to the metal/oxide material due to the very porous coating. On the contrary, at $\mathrm{pH} 0$, the electrical response is mainly due to the $\mathrm{PPy} / \mathrm{PW}_{12} \mathrm{O}_{40}{ }^{3-}$ coating. Moreover, table 2 shows how the resistances obtained for the $\mathrm{pH} 0$ solution are lower than the $\mathrm{pH} 13$ ones. $\mathrm{Rf} / \mathrm{s}$ at $\mathrm{pH} 0$ is due to polymer/electrolyte interface, while a higher value for Rox is due to metal/oxide interface. In this way, the ionic transfer is better for the polymeric coating instead of oxide one. The diffusion of species through the coating is faster than the ion-electron transfer on the steel/electrolyte interface. At $\mathrm{pH} 13$, the proton conductivity of 
$\mathrm{PW}_{12} \mathrm{O}_{40}{ }^{3-}$ disappears, since this anion decomposes and it is not present in the coating. In our previous paper [18] we deposited $\mathrm{PPy} / \mathrm{PW}_{12} \mathrm{O}_{40}{ }^{3-}$ on textile fabrics and values for the film electronic conductivity could be obtained. With the increase of $\mathrm{pH}$, the film electronic conductivity decreased. In this paper, as polypyrrole is in de-doped state ( $\mathrm{pH}$ 13), the electronic conductivity decrease significantly in comparison with $\mathrm{pH} 0$. These results are very interesting from the point of view of applying these $\mathrm{PPy} / \mathrm{PW}_{12} \mathrm{O}_{40}{ }^{3-}$ coated electrodes to treat textile wastewaters. Textile wastewaters treatment by electrocatalytic methods is one of our main research lines. More work is in progress in order to elucidate the best conditions for these electrodes in electrochemical treatments of textile wastewaters. 

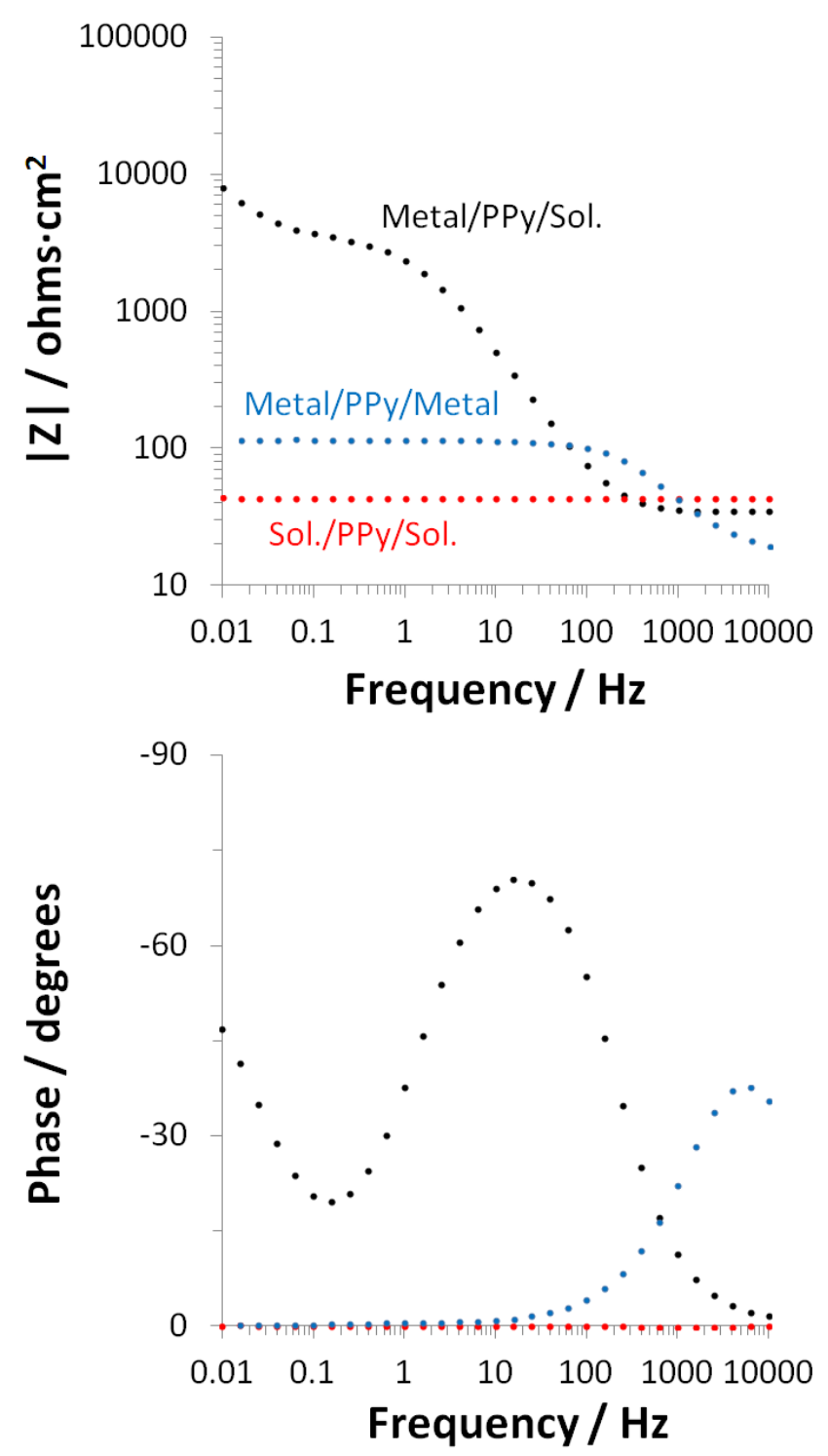

Fig. 10. Bode plots for PPy/PW ${ }_{12} \mathrm{O}_{40}{ }^{3-}$ films in different configurations: • Metal/PPy/pH 13 solution; • pH 13 solution/PPy/pH 13 solution; • Metal/PPy/Metal. Exposed electrode area: $1 \mathrm{~cm}^{2}$. Frequency range from $10^{4}$ to $10^{-2} \mathrm{~Hz}$.

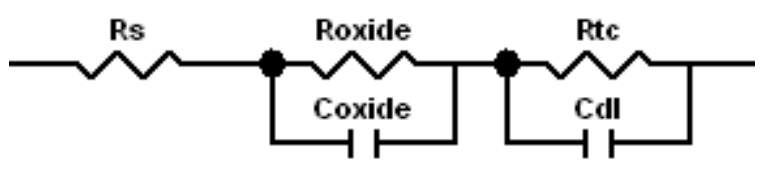


Fig. 11. Electrical circuit for stainless steel electrode coated of $\mathrm{PPy} / \mathrm{PW}_{12} \mathrm{O}_{40}{ }^{3-}$ in $0.1 \mathrm{M}$ $\mathrm{NaOH}+0.1 \mathrm{M} \mathrm{Na}_{2} \mathrm{SO}_{4}(\mathrm{pH} \sim 13)$ solution.

Table 2. Results of the fitting of impedance data of metal/PPy-PW ${ }_{12} \mathrm{O}_{40}{ }^{3-} /$ solution configuration in $0.5 \mathrm{M} \mathrm{H}_{2} \mathrm{SO}_{4}(\mathrm{pH} \sim 0)$ and $0.1 \mathrm{M} \mathrm{Na}_{2} \mathrm{SO}_{4}+0.1 \mathrm{M} \mathrm{NaOH}(\mathrm{pH} \sim 13)$ solutions. Exposed electrode area: $1 \mathrm{~cm}^{2}$. Frequency range from $10^{4}$ to $10^{-2} \mathrm{~Hz}$.

\begin{tabular}{|lclc|}
\hline pH 0 & \multicolumn{3}{l|}{$\mathrm{pH} 13$} \\
\hline $\operatorname{Rs}\left(\Omega \cdot \mathrm{cm}^{2}\right)$ & 13 & $\operatorname{Rpol}\left(\Omega \cdot \mathrm{cm}^{2}\right)$ & 36 \\
$\operatorname{Rf} / \mathrm{s}\left(\Omega \cdot \mathrm{cm}^{2}\right)$ & 9 & $\operatorname{Rox}\left(\Omega \cdot \mathrm{cm}^{2}\right)$ & 3328 \\
$\mathrm{Cf} / \mathrm{s}\left(\mathrm{F} / \mathrm{cm}^{2}\right)$ & $0.9 \cdot 10^{-5}$ & $\operatorname{Cox}\left(\mathrm{F} / \mathrm{cm}^{2}\right)$ & $3.1 \cdot 10^{-5}$ \\
Wo-R $\left(\Omega \cdot \mathrm{cm}^{2}\right)$ & 64 & $\operatorname{Rt}\left(\Omega \cdot \mathrm{cm}^{2}\right)$ & 32732 \\
Wo-T $(\mathrm{s})$ & 0.7 & $\operatorname{Cd}\left(\mathrm{F} / \mathrm{cm}^{2}\right)$ & 0.0028 \\
Wo-P & 0.5 & & \\
\hline
\end{tabular}

\section{Conclusions}

$\mathrm{PPy} / \mathrm{PW}_{12} \mathrm{O}_{40}{ }^{3-}$ membranes deliver higher ionic exchange rates when they are immersed in more concentrated $\mathrm{NaCl}$ solutions. The counter-ion diffusion within the membrane is also faster in more concentrated solutions.

Counter-ions of great size hinder the ionic exchange and the counter-ion diffusion in the $\mathrm{PPy} / \mathrm{PW}_{12} \mathrm{O}_{40}{ }^{3-}$ membranes.

PPy $/ \mathrm{PW}_{12} \mathrm{O}_{40}{ }^{3-}$ free-standing films obtained electrochemically present semiconducting nature and the activation energy by Arrhenius model was $170 \mathrm{meV}$. PPy/ $/ \mathrm{PW}_{12} \mathrm{O}_{40}{ }^{3-}$ films chemically deposited on polyester fabric present also semiconducting nature. The activation energy by the same model was $44.4 \mathrm{meV}$.

EDX and FTIR-ATR analysis show the decomposition of $\mathrm{PW}_{12} \mathrm{O}_{40}{ }^{3-}$ at $\mathrm{pH} 13$. 
The electrical conduction developed through coatings in strong acid solution $(0.5 \mathrm{M}$ $\mathrm{H}_{2} \mathrm{SO}_{4}$ ) is controlled by finite-length diffusion processes with reflective boundary conditions. The behavior changes completely when the same coated electrode is immersed for 1 hour in strong basic solution. The proton conductivity of $\mathrm{PW}_{12} \mathrm{O}_{40}{ }^{3-}$ disappears, since this anion decomposes at $\mathrm{pH} 13$ and it is not present in the coatings. In addition, the film electronic conductivity decreases considerably in comparison with $\mathrm{pH}$ 0 . In this case, the coating structure is very porous and the electrical signal mainly goes through the oxide layer (Fe and $\mathrm{Cr}$ oxides) and the stainless steel/electrolyte interface (at the base of the pores of the oxide layer).

In this initial study, multifunctional $\mathrm{PPy} / \mathrm{PW}_{12} \mathrm{O}_{40}{ }^{3-}$ membranes with different electric pathways via $\mathrm{pH}$ modulation have been prepared. This opens the way to design organicinorganic membranes to yield both smart textiles fabrics and new materials to wastewaters treatment by electrochemical techniques. Our research group has already obtained smart textile fabrics with LED's mounted in different fabrics and electronic circuits embroidered in leather.

\section{Acknowledgements}

Authors thank to the Spanish Ministerio de Ciencia e Innovación (contract CTM201123583) and Universitat Politècnica de València (Primeros Proyectos de Investigación (PAID-06-10)) for the financial support. J. Molina is grateful to the Conselleria d'Educació, Formació i Ocupació (Generalitat Valenciana) for the Programa VALi+D Postdoctoral Fellowship. 


\section{References}

[1] P. Gómez-Romero, Adv. Mater. 13 (2001) 163-174.

[2] H. Nguyen Thi Le, B. Garcia, C. Deslouis, Q. Le Xuan, Electrochim. Acta 46 (2001) $4259-4272$

[3] P. Gómez-Romero, J.A. Asensio, S. Borrós, Electrochim. Acta 50 (2005) 47154720.

[4] P. Gómez-Romero, M. Lira-Cantú, Adv. Mater. 9 (1997) 144-147.

[5] N. Casañ-Pastor, P. Gómez-Romero, Front. Biosci. 9 (2004) 1759-1770.

[6] A.F. Diaz, J. Bargon, Handbook of Conducting Polymers, Vol. 1, Marcel Dekker, New York, 1986.

[7] C. Ehrenbeck, K. Jüttner, S. Ludwig, G. Paasch, Electrochim. Acta 43 (1998) 27812789.

[8] C. Ehrenbeck, K. Jüttner, Electrochim. Acta 41 (1996) 1815-1823.

[9] J. Tietje-Girault, C. Ponce de León, F.C. Walsh, Surf. Coat. Technol. 201 (2007) 6025-6034.

[10] C. Deslouis, M.M. Musiani, B. Tribollet, M.A. Vorotyntsev, J. Electrochem. Soc. 142 (1995) 1902-1908.

[11] C. Deslouis, T. El Moustafid, M.M. Musiani, B. Tribollet, Electrochim. Acta 41 (1996) 1343-1349.

[12] C. Deslouis, M.M. Musiani, B. Tribollet, J. Phys. Chem. 100 (1996) 8994-8999.

[13] C. Deslouis, M.M. Musiani, B. Tribollet, Synth. Met. 84 (1997) 827-828.

[14] J. Molina, J. Fernández, J.C. Inés, A.I. del Río, J. Bonastre, F. Cases, Electrochim. Acta 93 (2013) 44-52. 
[15] J. Molina, M.F. Esteves, J. Fernández, J. Bonastre, F. Cases, Eur. Polym. J. 47 (2011) 2003-2015.

[16] J. Molina, A.I. del Río, J. Bonastre, F. Cases, Synth. Met. 160 (2010) 99-107.

[17] J. Molina, J. Fernández, A.I. del Río, J. Bonastre, F. Cases, Synth. Met. 161 (2011) 953-963.

[18] J. Bonastre, J. Molina, A.I. del Río, J.C. Galván, F. Cases, Synth. Met. 161 (2011) $1958-1965$.

[19] J. Molina, A.I. del Río, J. Bonastre, F. Cases, Eur. Polym. J. 44 (2008) 2087-2098. [20] J. Molina, J. Fernández, A.I. del Río, J. Bonastre, F. Cases, Appl. Surf. Sci. 257 (2011) 10056-10064.

[21] J. Molina, A.I. del Río, J. Bonastre, F. Cases, Eur. Polym. J. 45 (2009) 1302-1315. [22] J. Molina, J. Fernández, A.I. del Río, R. Lapuente, J. Bonastre, F. Cases, Polym. Degrad. Stabil. 95 (2010) 2574-2583.

[23] E. Romero, J. Molina, A.I. del Río, J. Bonastre, F. Cases, Text. Res. J. 81 (2011) $1427-1437$

[24] J. Fernández, J. Molina, A.I. del Río, J. Bonastre, F. Cases, Int. J. Electrochem. Sci. 7 (2012) 10175-10189.

[25] J. Molina, F.R. Oliveira, A.P. Souto, M.F. Esteves, J. Bonastre, F. Cases, J. Appl. Polym. Sci. 129 (2013) 422-433.

[26] A.I. del Río, J. Fernández, J. Molina, J. Bonastre, F. Cases, Electrochim. Acta 55 (2010) 7282-7289.

[27] A.I. del Río, J. Fernández, J. Molina, J. Bonastre, F. Cases, Desalination 273 (2011) 428-435. 
[28] A.I. del Río, J. Molina, J. Bonastre, F. Cases, J. Hazard. Mater. 172 (2009) 187195.

[29] J. Molina, J. Fernández, A.I. del Río, J. Bonastre, F. Cases, Appl. Surf. Sci. 258 (2012) 6246-6256.

[30] A.I. del Río, J. Molina, J. Bonastre, F. Cases, Chemosphere 75 (2009) 1329-1337.

[31] A.I. del Río-García, M.J. Benimeli, J. Molina, J. Bonastre, F. Cases, Int. J.

Electrochem. Sci. 7 (2012) 13074-13092.

[32] E. Romero, J. Molina, A.I. del Río, J. Bonastre, F. Cases, Textile Res. J. 81 (2011) $1427-1437$

[33] J. Bonastre, P. Garcés, J.C. Galván, F. Cases, Prog. Org. Coat. 66 (2009) 235-241.

[34] C.A. Ferreira, S. Aeiyach, J.J. Aaron, P.C. Lacaze, Electrochim. Acta 41 (1996) 1801-1809.

[35] T.F. Otero, S.A. Cheng, F. Huerta, J. Phys. Chem. B 104 (2000) 10522-10527.

[36] R. Friend, Nature 441 (2006) 37.

[37] K. Lee, S. Cho, S.H. Park, A.J. Heeger, C.-W. Lee, S.-H. Lee, Nature 441 (2006) $65-68$.

[38] V. Shaktawat, N. Jain, R. Saxena, N.S. Saxena, K. Sharma, T.P. Sharma, Polym. Bull. 57 (2006) 535-543.

[39] M. Taunk, A. Kapil, S. Chand, J. Mater. Sci.-Mater. Electron. 22 (2011) 136-142.

[40] P.S. Abthagir, R. Saraswathi, Mater. Chem. Phys. 92 (2005) 21-26.

[41] M.A. Vorotyntsev, C. Deslouis, M.M. Musiani, B. Tribollet, K. Aoki, Electrochim. Acta 44 (1999) 2105-2115.

[42] Z. Zu, R. Tain, C. Rhodes, Can. J. Chem. 81 (2003) 1044-1050. 
[43] E. López-Salinas, J.G. Hernández-Cortéz, Ma.A. Cortés Jácome, J. Navarrete,

Ma.E. Llanos, A. Vázquez, H. Armendáriz, T. López, Appl. Catal. A-Gen. 175 (1998) 43-53.

[44] L. Dall'Acqua, C. Tonin, A. Varesano, M. Canetti, W. Porzio, M. Catellani, Synth. Met. 156 (2006) 379-386.

[45] L. Dall'Acqua, C. Tonin, R. Peila, F. Ferrero, M. Catellani, Synth. Met. 146 (2004) 213-221.

[46] T. K. Vishnuvardhan, V.R. Kulkarni, C. Basavaraja, S.C. Raghavendra, Bull. Mater. Sci. 29 (2006) 77-83.

[47] T.F. Otero, S.A. Cheng, D. Alonso, F. Huerta, J. Phys. Chem. B 104 (2000) 1052810533.

[48] W. Feng, T.R. Zhang, Y. Liu, R. Lu, Y.Y. Zhao, J. Mater. Sci. 38 (2003) $1045-$ 1048.

[49] P.A. Jalil, M. Faiz, N. Tabet, N.M. Hamdan, Z. Hussain, J. Catal. 217 (2003) 292297.

\section{Figure captions}

Fig. 1. Current transient curve for potentiostatic synthesis of $\mathrm{PPy} / \mathrm{PW}_{12} \mathrm{O}_{4}{ }^{3-}$ on stainless steel. Acetonitrile medium, $0.01 \mathrm{M} \mathrm{H}_{3} \mathrm{PW}_{12} \mathrm{O}_{40}, 0.2 \mathrm{M}$ pirrol. Start potential: $-0.289 \mathrm{~V}$, synthesis potential: $+0.86 \mathrm{~V}, \mathrm{Q}=0.5 \mathrm{C} \mathrm{cm}^{-2}$.

Fig. 2. Plot of $\mathrm{Ln}(\sigma)$ vs. $1000 / \mathrm{T}$ for the film of $\mathrm{PPy} / \mathrm{PW}_{12} \mathrm{O}_{40}{ }^{3-}$. 
Fig. 3. Electrical circuit for free-standing films in symmetrical configuration solution/membrane/solution

Fig. 4. Nyquist plot for $\mathrm{PPy} / \mathrm{PW}_{12} \mathrm{O}_{40}{ }^{3-}$ membrane in $0.1 \mathrm{M} \mathrm{NaCl}$ solution. Exposed electrode area: $1 \mathrm{~cm}^{2}$. Frequency range from $10^{4}$ to $10^{-2} \mathrm{~Hz} \cdot \bullet$ Experimental data. Fitting data.

Fig. 5. Bode plots for $\mathrm{PPy} / \mathrm{PW}_{12} \mathrm{O}_{40}{ }^{3-}$ membranes in different $\mathrm{NaCl}$ solutions. Exposed electrode area: $1 \mathrm{~cm}^{2}$. Frequency range from $10^{4}$ to $10^{-2} \mathrm{~Hz}$.

Fig. 6. Cyclic voltammograms obtained in a 4-electrode arrangement in $0.5 \mathrm{M} \mathrm{H}_{2} \mathrm{SO}_{4}$; scan rate: $50 \mathrm{mV} \cdot \mathrm{s}^{-1} .-$ Without $\mathrm{PPy} / \mathrm{PW}_{12} \mathrm{O}_{40}{ }^{3-}$ membrane; - with $\mathrm{PPy} / \mathrm{PW}_{12} \mathrm{O}_{40}{ }^{3-}$ membrane.

Fig. 7. EDX spectra and micrographs of: (a) $\mathrm{PPy} / \mathrm{PW}_{12} \mathrm{O}_{40}{ }^{3-}$, (b) and (c) $\mathrm{PPy} / / \mathrm{PW}_{12} \mathrm{O}_{40}{ }^{3-}$ $+1 \mathrm{~h}$ contact with $\mathrm{pH} 13$ solution.

Fig. 8. FTIR-ATR spectrum of $\mathrm{PPy} / \mathrm{PW}_{12} \mathrm{O}_{40}{ }^{3-}$ and $\mathrm{PPy} / \mathrm{PW}_{12} \mathrm{O}_{40}{ }^{3-}+1 \mathrm{~h} \mathrm{pH} 13$. Resolution $4 \mathrm{~cm}^{-1}, 100$ scans.

Fig. 9. Nyquist plots for PPy/ $\mathrm{PW}_{12} \mathrm{O}_{40}{ }^{3-}$ films in different configurations: • Metal/PPy/0.5 M H $\mathrm{SO}_{4} ; \bullet 0.5 \mathrm{M} \mathrm{H}_{2} \mathrm{SO}_{4} / \mathrm{PPy} / 0.5 \mathrm{M} \mathrm{H}_{2} \mathrm{SO}_{4} ; \cdot$ Metal/PPy/Metal. Exposed electrode area: $1 \mathrm{~cm}^{2}$. Frequency range from $10^{4}$ to $10^{-2} \mathrm{~Hz}$. 
Fig. 10. Bode plots for PPy/PW ${ }_{12} \mathrm{O}_{40}{ }^{3-}$ films in different configurations: • Metal/PPy/pH 13 solution; • pH 13 solution/PPy/pH 13 solution; • Metal/PPy/Metal. Exposed electrode area: $1 \mathrm{~cm}^{2}$. Frequency range from $10^{4}$ to $10^{-2} \mathrm{~Hz}$.

Fig. 11. Electrical circuit for stainless steel electrode coated of $\mathrm{PPy} / \mathrm{PW}_{12} \mathrm{O}_{40}{ }^{3-}$ in $0.1 \mathrm{M}$ $\mathrm{NaOH}+0.1 \mathrm{M} \mathrm{Na}_{2} \mathrm{SO}_{4}(\mathrm{pH} \sim 13)$ solution.

\section{Table captions}

Table 1. Results of the fitting of impedance data of $\mathrm{PPy} / \mathrm{PW}_{12} \mathrm{O}_{40}{ }^{3-}$ membranes in different solutions. Exposed electrode area: $1 \mathrm{~cm}^{2}$. Frequency range from $10^{4}$ to $10^{-2} \mathrm{~Hz}$.

Table 2. Results of the fitting of impedance data of metal/PPy- $\mathrm{PW}_{12} \mathrm{O}_{40}{ }^{3-} /$ solution configuration in $0.5 \mathrm{M} \mathrm{H}_{2} \mathrm{SO}_{4}(\mathrm{pH} \sim 0)$ and $0.1 \mathrm{M} \mathrm{Na}_{2} \mathrm{SO}_{4}+0.1 \mathrm{M} \mathrm{NaOH}(\mathrm{pH} \sim 13)$ solutions. Exposed electrode area: $1 \mathrm{~cm}^{2}$. Frequency range from $10^{4}$ to $10^{-2} \mathrm{~Hz}$. 